\title{
Phosphorus Removal From Aqueous Solution By Adsorption Onto La-modified Clinoptilolite
}

\author{
Can $\mathrm{TU}^{1}$, Shibo WANG ${ }^{1}$, Weixia QIU ${ }^{1}$, Ruosong XIE ${ }^{1}$, Bocai HU ${ }^{1}$, Guangfei QU ${ }^{1, *}$ \\ and Ping NING ${ }^{1}$ \\ ${ }^{1}$ Faculty of Environmental Science and Engineering, Kunming University of Science \& Technology, \\ Kunming, Yunnan 650500, China.
}

\begin{abstract}
A La-modified clinoptilolite adsorbent was developed for phosphorus removal from aqueous solution. The effects of operational parameters such as $\mathrm{pH}$, adsorbent dosage, contact time and temperature on phosphorus adsorption were investigated. The results showed that the phosphorus removal ratio of modified clinoptilolite (99.45\%) was significantly improved, which was over triple than that of natural ones $(31.50 \%)$ under optimum conditions. The adsorption process was well described by the pseudo-second-order kinetic model. Moreover, the adsorption data closely fitted the Freundlich isotherm model. The proper $\mathrm{pH}$ for phosphorus removal ranged from 5 to 8 . The adsorption process was appeared to be controlled by chemical precipitation. The mechanism might involve ion complexation during subsequent adsorption of phosphorus on lanthanum hydroxides. It cost modified clinoptilolite less time to reach equilibrium. The application of modified clinoptilolite is available in wastewater treatment.
\end{abstract}

\section{Introduction}

Water is a basic necessity for human being along with food and air. However, industrial development, lagged agriculture and urbanization cause severe water pollution. ${ }^{[1]}$ Facing today's water quality management, eutrophication is a serious issue, which caused by the excessive phosphorus and nitrogen in water body. ${ }^{[2]}$ Eutrophication may cause aquatic plants (e.g. algae) or cyanobacterial blooms. Blooms itself not only contains a variety of potent toxins and its blooms can cause increased water turbidity, anoxia, fish kills and other phenomena, and due to changes in the food web resulting stench. It means that the blooms may lead to serious environmental problems and risk to human health. ${ }^{[3]}$ Control eutrophication and reduce its harm to humans are key challenges to water quality managers. It is believed by majority of researchers that phosphorus is the major limiting factor for eutrophication, so it is more efficient to control the content of phosphorus rather than nitrogen. ${ }^{[4]}$ Recently, because of the increasingly stringent requirements of phosphorus emissions so the removal of phosphorus in wastewater technology has a lot. Removing phosphorus's representative methods include adsorption, ion exchange, precipitation and biological removal. ${ }^{[5]}$ The adsorption process which is recognized as the most effective and

* Corresponding author:qgflab@sina.com 
widely used in sewage treatment process, the mechanism of the adsorption is through the multi-component fluid (gas or liquid) mixture is attracted to the surface of a solid adsorbent and forms attachments via physical or chemical bonds. ${ }^{[6]}$ Thus, finding out the selective adsorbents which are simple operation and can be adapted to different wastewater composition for phosphorus removal is necessary, extensive researches have been carried out.

Nowadays, a number of different solid adsorbents were considered to be used in reducing phosphorus levels. Although they have various advantages in applications, but they also exist a similar disadvantage when the solution $\mathrm{pH}$ and redox conditions was changed the adsorbed phosphorus can be re-released. ${ }^{[7]}$ Many researches have been reported that clinoptilolite commonly used in wastewater treatment because of its large specific surface area and highly selective adsorption. However, natural clinoptilolite with several deficiencies such as non-uniform channels and high content of impurity results in poor adsorption efficiency in the process of wastewater treatment. Therefore, it should be modified and further purification. Anionic properties on the zeolitic surface can efficiently be improved using surfactants modification. ${ }^{[8]}$ Meanwhile, phosphate precipitation by lanthanum is more effective than either ferric or aluminium salts over a wide $\mathrm{pH}$ range. The forming lanthanum - phosphate complexes are highly insoluble. Tokunaga et al remove arsenic ( $\mathrm{V}$ ) ion from aqueous solution by lanthanum compounds, the experimental results are very impressive. ${ }^{[9]}$

Thus, in present study, lanthanum modification of natural clinoptilolite was carried out. As in most adsorption processes in the aqueous solution, any changes in the chemical properties of solution can lead to changes in other equilibrium in the adsorption system. The purposes of this study were as following: firstly, to investigate the effect of influence factors on phosphorus removal efficiency by clinoptilolite. Secondly, to further understand the adsorption mechanism of La-modified clinoptilolite. Thirdly, to check the effectiveness of modified clinoptilolite in reducing phosphorus concentration from real wastewater.

\section{Materials and Methods}

\subsection{Raw Materials}

The natural clinoptilolite used in this study was purchased from Yanshan, Yunnan province, China. X-ray diffraction (XRD) analysis indicated that its composition was mainly clinoptilolite, and concomitant materials including little quartz, mica and orthoclase. The elemental components of natural and modified clinoptilolite were shown in Table 1.

Table 1 Results Of Surface Spectrum Analysis Of Natural And Modified Clinoptilolite

\begin{tabular}{|c|c|c|}
\hline Elements & Natural clinoptilolite [wt \%] & Modified clinoptilolite [wt \%] \\
\hline $\mathrm{O}$ & 27.33 & 26.53 \\
\hline $\mathrm{Na}$ & - & 1.03 \\
\hline $\mathrm{Mg}$ & 1.37 & 0.96 \\
\hline $\mathrm{Al}$ & 8.30 & 8.64 \\
\hline
\end{tabular}




\begin{tabular}{|c|c|c|}
\hline $\mathrm{Si}$ & 27.33 & 27.26 \\
\hline $\mathrm{K}$ & 2.41 & 2.52 \\
\hline $\mathrm{Ca}$ & 1.80 & 0.73 \\
\hline $\mathrm{La}$ & - & 4.01 \\
\hline $\mathrm{Fe}$ & 2.58 & - \\
\hline
\end{tabular}

\subsection{Water Samples}

The simulated wastewater sample was prepared containing phosphates of $50 \mathrm{mg} \cdot \mathrm{L}^{-1}$ which spiked with $\mathrm{P}$ in the form of a solution of $\mathrm{KH}_{2} \mathrm{PO}_{4}$, the data is approximately representative of the concentration in real wastewater. The phosphorus content mentioned in this paper was expressed as $\mathrm{mg} \mathrm{P} \cdot \mathrm{L}^{-1}$ instead of $\mathrm{mg} \mathrm{K \textrm {K } _ { 2 }} \mathrm{PO}_{4} \cdot \mathrm{L}^{-1}$. The real bovine urine wastewater was obtained from Dali, Yunnan. The concentration of phosphorus is $56.92 \mathrm{mg} \cdot \mathrm{L}^{-1}$ and the $\mathrm{pH}$ is 8.2 .

\subsection{Modification of the Natural Clinoptilolite}

Modification of the natural clinoptilolite was accomplished according to Lin hai et al. ${ }^{[10]}$ Firstly, the natural clinoptilolite was washed three times with distilled water in order to remove dust and soluble salt on the surface, then crushed and sieved through 40 stainless-steel mesh sieve to obtain the required particles after air-drying. The La-form was prepared through a first full ionic exchange with $\mathrm{Na}^{+}$ions $\left(\mathrm{L} / \mathrm{S}=50 \mathrm{mg} \cdot \mathrm{L}^{-1}, 213 \mathrm{~K}, 2 \mathrm{~h}, \mathrm{NaCl}\right.$ $2 \mathrm{wt} \%)$, followed by a subsequent exchange with $\mathrm{La}^{3+}$ ions $\left(\mathrm{L} / \mathrm{S}=10 \mathrm{mg} \cdot \mathrm{L}^{-1}, 213 \mathrm{~K}, 2 \mathrm{~h}\right.$, $\mathrm{pH}=10, \mathrm{LaCl}_{3} 0.4 \mathrm{wt} \%$ ). Then it was separated by filtration and washed with distilled water. After cleanness, the solid was oven-dried at $383 \mathrm{~K}$ and sequentially the modified clinoptilolite was calcined at $473 \mathrm{~K}$ for $1.5 \mathrm{~h}$ to dehydrate and remove the impurities. Finally, the modified clinoptilolite was sealed and reserved in a dry place for further experiments. All chemical reagents used in this experiment were analytical grade and used without further purification.

\subsection{Adsorption Experiment}

Batch adsorption studies were carried out in a $250 \mathrm{~mL}$ conical flask containing $50 \mathrm{~mL}$ simulated wastewater and a certain amount of adsorbent, in three replications. And each experimental result was obtained by averaging the data for three parallel experiments. Two clinoptilolite phosphate adsorbents were used, namely the raw form and the La-modified form. The initial $\mathrm{pH}$ of phosphorus solution has been adjusted to a definite value using $\mathrm{HCl}$ $(0.1 \mathrm{M})$ or $\mathrm{NaOH}(0.1 \mathrm{M})$ solutions. The adsorption tests were conducted in a thermostatic water bath oscillator for desired time and temperature. At the end of each equilibration period, the liquid sample was taken to detect phosphorus content after centrifugation. The influence of specific process parameters such as $\mathrm{pH}$, adsorbent dosages, contact time and temperature on phosphorus adsorption was investigated by changing one parameter and keeping other parameters constant in order to optimize the adsorption process. 


\subsection{Analytical Methods}

The specific surface area of absorbents was evaluated by adopting a Brunauer-Emmett-Teller (BET) surface area measurement (Micromeritics ASAP200) with $\mathrm{N}_{2}$ as the detection of gas. The X-ray Diffraction (XRD) patterns were recorded using D8 ADVANCE (BRUKER-AXS Company) with $\mathrm{Cu} \mathrm{K \alpha}$ filtered radiation $(30 \mathrm{kV}, 15 \mathrm{~mA}$ ). FT-IR measurements were performed on a Nicolet FT-IR 380 instrument (Thermo Scientific Co., Ltd., USA).In addition, the morphology of natural and modified clinoptilolite was monitored with a scanning electron microscopy (SEM, Super Scan SSX-550, Japan). Energy Dispersive Spectrometer (EDS) analysis were conducted to provide information about elemental composition of the natural and modified clinoptilolite. The $\mathrm{pH}$ values of solution were determined by Leici PHS-3C $\mathrm{pH}$ meter. The concentration of phosphorus in wastewater solution was analyzed with a UV-vis spectrophotometry (TU-1901 ultraviolet spectrophotometer) using the molybdenum antimony method.

The experimental results were evaluated by the percentage removal ratio of phosphorus (R) and adsorption capacity $\left(\mathrm{K}_{\mathrm{d}}\right)$. They can be calculated using following equations respectively: ${ }^{[11]}$

$$
\begin{aligned}
& R=\frac{C_{0}-C_{t}}{C_{0}} \times 100 \% \\
& K_{d}=\frac{\left(C_{0}-C_{t}\right) \times V}{m} .
\end{aligned}
$$

where $\mathrm{C}_{0}$ and $\mathrm{C}_{\mathrm{t}}$ are the concentrations in solution $\left(\mathrm{mg} \cdot \mathrm{L}^{-1}\right)$ at the beginning and after a contact time $t$ of the experiment. $\mathrm{V}$ represents the volume of the solution in $\mathrm{L}$ and $\mathrm{m}$ is the weight of the adsorbent in $\mathrm{g}$.

\subsection{Adsorption Isotherm Experiment}

$5 \mathrm{~g}$ natural or modified clinoptilolite and $50 \mathrm{~mL}$ simulated water containing varying concentration of phosphorus $\left(5,10,20,80,120,160,180,240 \mathrm{mg} \cdot \mathrm{L}^{-1}\right)$ were placed in corresponding $150 \mathrm{~mL}$ Erlenmeyer flasks. The $\mathrm{pH}$ was adjusted to the desired value 8.0. The flasks were then placed in the oscillator for $2.0 \mathrm{~h}$ at $303 \mathrm{~K}$ with intermittent shaking to achieve adsorption equilibrium. After equilibration, the solution was centrifuged and the concentration of phosphorus in supernatant was measured. The amount of adsorbed phosphorus was calculated by the difference between the amount added and that found in solution at equilibrium.

The Langmuir and Freundlich isotherm models were used to fit the adsorption equilibrium data. The Langmuir adsorption model is expressed as the following nonlinear equation to describe the adsorption processes between solid-liquid interfaces: ${ }^{[12]}$

$$
\frac{C_{e}}{q_{e}}=\frac{1}{K_{L} q_{m}}+\frac{C_{e}}{q_{m}} .
$$

where $\mathrm{C}_{\mathrm{e}}$ represents equilibrium phosphorus concentration $\left(\mathrm{mg} \cdot \mathrm{L}^{-1}\right)$ of solution, $\mathrm{q}_{\mathrm{e}}$ is the amount of phosphorus adsorbed/weight of adsorbent $\left(\mathrm{mg} \cdot \mathrm{g}^{-1}\right)$ at equilibrium, $\mathrm{q}_{\mathrm{m}}$ is the maximum adsorption capacity of the adsorbent $\left(\mathrm{mg} \cdot \mathrm{g}^{-1}\right), \mathrm{K}_{\mathrm{L}}$ is the Langmuir coefficient. 
Furthermore, the feasibility of adsorption process is reflected by distribution coefficient

$\mathrm{R}_{\mathrm{L}}$, which can be calculated using following equation according to Weber and Chakraborti.

$$
R_{L}=\frac{1}{1+K_{L} C_{0}}
$$

where $\mathrm{C}_{0}$ is the highest initial phosphorus concentration of solution $\left(\mathrm{mg} \cdot \mathrm{L}^{-1}\right)$.

The Freundlich isotherm model as the second most widely used mathematical description gives an expression encompassing the surface heterogeneity and the exponential distribution of active sites and their energies. The adsorption model is represented as follows: ${ }^{[14]}$

$$
\log q_{e}=\log K_{F}+\frac{1}{n} \log C_{e} .
$$

where $K_{F}$ and $n$ are the Freundlich constants. The values of $K_{F}$ and $1 / n$ are determined from the intercept and slope of linear plot of $\log \mathrm{q}_{\mathrm{e}}$ versus $\log \mathrm{C}_{\mathrm{e}}$, respectively.

To evaluate the goodness of fit of each equation, the correlation coefficient $\left(R^{2}\right)$ of the estimate model were used.

\subsection{Adsorption Kinetics Experiment}

Approximately $400 \mathrm{~mL}$ bovine urine wastewater was measured and placed in a 1000 $\mathrm{mL}$ Erlenmeyer flask. The optimum operational conditions were adopted according to the results of experiments which obtained before. After mixing up real wastewater with modified clinoptilolite, the solution was oscillated for $3.0 \mathrm{~h}$ at $303 \mathrm{~K}$ without $\mathrm{pH}$ adjustment. The sample which was obtained at a certain interval of time was centrifuged to separate the supernatant and solid phases. Then the concentration of phosphorus in supernatant was measured.

The pseudo-first-order (Equation (6)) and pseudo-second-order (Equation (7)) kinetics models have been widely applied to describe adsorption system. The phosphorus adsorption process was described using following linear form of the model: ${ }^{[15,16]}$

$$
\begin{gathered}
\ln \left(Q_{e}-Q_{t}\right)=\ln Q_{t}-k_{1} t . \\
\frac{t}{Q_{t}}=\frac{1}{k_{2} Q_{e}^{2}}+\frac{t}{Q_{e}} .
\end{gathered}
$$

where $\mathrm{k}_{1}, \mathrm{k}_{2}$ are the rate constant of pseudo-first-order and pseudo-second-order kinetics model $\left(\mathrm{min}^{-1}\right.$ and $\left.\mathrm{g} \cdot \mathrm{mg}^{-1} \cdot \mathrm{min}^{-1}\right)$, respectively. $\mathrm{Q}_{\mathrm{e}}, \mathrm{Q}_{\mathrm{t}}$ represent the values of adsorption capacity $\left(\mathrm{mg} \cdot \mathrm{g}^{-1}\right)$ at equilibrium or specific time, respectively.

\section{Results and Discussion}

\subsection{Materials Characterization}

The SEM and EDS results of natural and modified clinoptilolite were compared. SEM images of materials before and after modification were presented in Figure.1. The figures 
showed that the surface of modified clinoptilolite was much rougher than that of natural one. The rough surface was conductive to promote adsorption capacity. In addition, the structure of modified clinoptilolite was a loose sponge and pores were significantly increased representing the increase in specific surface area, which would be beneficial for ion exchange. Also the specific surface area and average pore size of natural clinoptilolite were $12.9065 \mathrm{~m}^{2} \cdot \mathrm{g}^{-1}$ and $15.4165 \mathrm{~nm}$, while that of the modified one were $13.6087 \mathrm{~m}^{2} \cdot \mathrm{g}^{-1}$ and $18.6497 \mathrm{~nm}$ according to BET analysis (dates were not shown). The results of computation correlated well with SEM images. The results of XRD (Figure.3 (a)) analyses showed that the degree of crystallinity was increased after modification (dates were not shown), which were in general agreement with previous SEM and BET studies. And the results of surface spectrum analysis were presented in Table 1. It could be seen that the concentration of iron ion in modified clinoptilolite was below the detection limit, and the content of magnesium ion decreased as well as calcium ion, while lanthanum and sodium ion obviously increased compared to the corresponding composition in natural ones. This phenomenon illustrated that lanthanum ion effectively loaded to the surface of natural clinoptilolite.
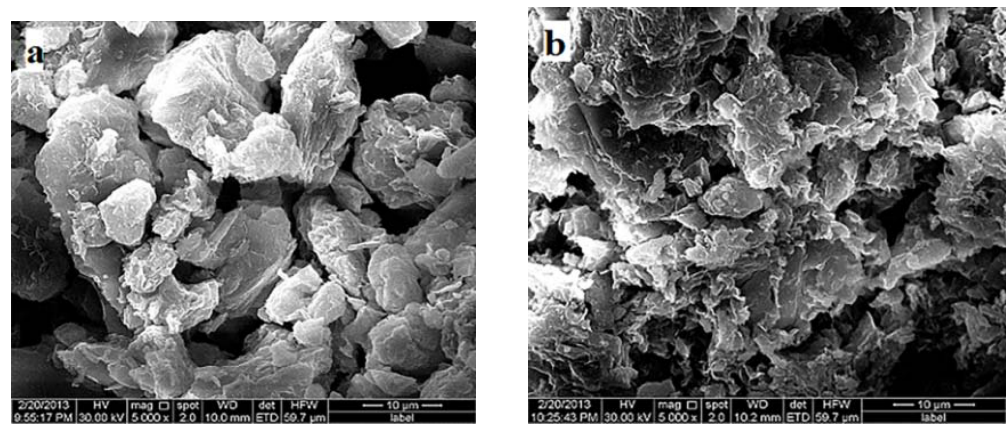

Figure.1 The SEM image of natural clinoptilolite (a) or modified clinoptilolite (b).

\subsection{Adsorption of Phosphorus from Stimulated Wastewater}

\subsection{The effect of $\mathrm{pH}$ on removal efficiency}

Adsorption studies were carried out at $\mathrm{pH}$ 5.0, 6.0, 7.0, 8.0, 9.0, 10.0 and 11.0 to find out the optimum $\mathrm{pH}$ for phosphorus removal. The experimental results were shown in Figure.2 (a). It could be observed that the removal ratio of phosphorus didn't change significantly over the $\mathrm{pH}$ value from 5.0 to 8.0 , all above $99 \%$, which were far higher than that of natural ones. On the other hand, when it came to natural clinoptilolite, the removal ratio of phosphorus increased with rising $\mathrm{pH}$ from the acidic to alkaline range. The phenomenon was quite different from the variation tendency of modified ones. The $\mathrm{pH}$ value of 8.0 was chosen as the best option in the following experiments because it is the closest value in comparison to the $\mathrm{pH}$ in real bovine urine wastewater. Moreover, this $\mathrm{pH}$ does least harm to the structure and property of adsorbent.

According to Schroeder ${ }^{[17]}$, the affinity of adsorbent for anions mainly depends on the anion's valence and size. The higher the valence and the smaller the hydrated ionic radius, the stronger is the adsorption. Soluble inorganic $\mathrm{P}$ may be presented in four different chemical forms when the $\mathrm{pH}$ value changes. When solution $\mathrm{pH}$ is less than $2, \mathrm{P}$ exists as $\mathrm{H}_{3} \mathrm{PO}_{4} ; \mathrm{pH}$ between 3 and 6.5 , the dominant chemical form is $\mathrm{H}_{2} \mathrm{PO}_{4}^{-}$; $\mathrm{pH}$ from 7.5 to 12 , $\mathrm{HPO}_{4}{ }^{2-}$ dominates; and $\mathrm{pH}$ greater than $12, \mathrm{P}$ presents in the form of $\mathrm{PO}_{4}{ }^{3-} .{ }^{[18]}$ Thus, the 
extent of phosphorus adsorbed in unit adsorbent would decrease with the increasing $\mathrm{pH}$ theoretically. However, the experimental results showed that there was almost similar removal ratio corresponding to $\mathrm{pH} 5.0,6.0,7.0$ and 8.0. While the $\mathrm{pH}$ was above 8.0, the adsorption capacity rapidly decreased probably due to the formation of lanthanum hydroxides. ${ }^{[19]} \mathrm{Jie} \mathrm{Xie}{ }^{[20]}$ has found that $\mathrm{OH}^{-}$as well as carbonate and bicarbonate ions could compete with phosphate for adsorption sites when the performance for phosphate removal by Lanthanum hydroxide decreased sharply with increasing $\mathrm{pH}$ more than 9 . So, this could be attributed to the formation of hydroxyl species of the lanthanum ions decreasing the number of phosphorus binding sites on the clinoptilolite surface. Several researchers claimed that hydroxide lanthanum had better performance than lanthanum oxide in phosphorus removal. So the exact mechanisms need further experiments to confirm. $\mathrm{Li}$ and Bowman reported that the anion adsorption mechanism on the surfactant-modified zeolite is anion exchange. ${ }^{[21]}$ Specifically, with the respect to the modified clinoptilolite, the phosphorus removal was due to lanthanum phosphate complexation reaction, which was held by electrostatic binding. Furthermore, the electrostatic binding was stronger for the polyvalent anions than the univalent anions with a smaller hydrated ionic radius. Thirdly, lanthanum ion combined with hydroxide ions existing in solution easily resulting in the formation of hydroxylated surface. To some extent, then the anion exchange process was occurred that the phosphate was exchanged for hydroxyl radicals. Based on these explanations and taking into account that the univalent and divalent $\mathrm{P}$ anions have similar hydrated ionic radius estimated at $0.4 \mathrm{~nm},{ }^{[22]}$ the decrease in $\mathrm{P}$ adsorption in response to a rise in $\mathrm{pH}$ could be due to the fact that the alkaline solution has changed the valence of lanthanum oxide. In addition, in alkaline solution the increased hydroxide ions would compete against phosphate ions for the adsorption sites on the adsorbent, resulting in the complexation action on lanthanum oxide being suppressed and the phosphorus fixation in adsorbent being reduced.

\subsection{The effect of adsorbent dosage on removal efficiency}

In this section, the influence of adsorbent dosage at 1.0, 3.0, 5.0, 7.0, 9.0 and $11.0 \mathrm{~g}$ on phosphorus removal was investigated. The experimental data was displayed in Figure. 2 (b). It was clearly showed that the removal ratio of phosphorus increased with adsorbent dosage. With adsorbent dosage increased from 1.0 to $9.0 \mathrm{~g}$, the removal ratio of phosphorus increased from $35.67 \%$ to $97.67 \%$ indicating the dependence of adsorption upon the availability of binding sites for phosphorus. Continue to increase the amount of adsorbent, the removal ratio was not increased any more, suggesting that the adsorbent was excess in solution, and there was no need to add. But in case of unmodified forms, the increase in phosphorus removal ratio was very small. The removal efficiency of phosphorus increased with the growing dosage of natural clinoptilolite and did not appear flat trend in the range of the experimental investigation, indicating that raw clinoptilolite couldn't adsorb phosphorus in the solution completely owning to its small adsorption capacity. As there was an insignificant change in the percentage adsorption as the amount of adsorbent was beyond $5 \mathrm{~g}$, so the optimum adsorbent dosage was determined to be $5 \mathrm{~g}$ considering the cost, the efficiency of treatment and other factors. This operation factor was used to all subsequent experiments.

\subsection{The effect of temperature on removal efficiency}

Experimental results concerning the effect of temperature at 293, 303, 313, 323 and $333 \mathrm{~K}$ on phosphorus removal ratio of natural and modified clinoptilolite were demonstrated in Figure.2 (c). The effect of temperature on adsorption capacity of natural 
clinoptilolite was much more significant compared to modified ones. The behavior of modified clinoptilolite was indeed expected to differ greatly from the natural ones, taking into account the completely different adsorption mechanisms, i.e. precipitation reaction held the main possession instead of anion exchange. Thus, temperature had little influence on adsorption efficiency of modified clinoptilolite. And the experimental results certainly confirmed this speculation. So far as natural clinoptilolite was concerned, the removal ratio of phosphorus increased with temperature. This phenomenon may be attributed to following reasons: Firstly, with the temperature increased, the adsorbent particles' diffusion rate (physically adsorbed) across the external boundary layer and in the internal pores was increased, because of the attractive forces between adsorbent surface and ions were weakened. Secondly, thermal agitation resulted in accelerating the retardation of the processes or some originally slow adsorption steps such as complex formation, association of ions, ion pairing and aggregation of molecules in the system. ${ }^{[23]}$ Thirdly, for endothermic adsorption, adsorption rate/amount of adsorbent would increase with temperature. Therefore the adsorption capacity was enhanced with temperature while the amount of adsorbent was certain. On the other hand, another reason leading to better adsorption efficiency at higher temperature was that some definite functional groups came off from adsorbent surface resulting in some adsorption site released.

\subsection{The effect of contact time on removal efficiency}

The effect of contact time on phosphorus removal of natural and modified clinoptilolite had been performed to find out the optimum adsorption time. The changes of $\mathrm{R}$ upon contact time were shown in Figure.2 (d). The experimental data revealed that phosphorus removal ratio increased with contact time until the equilibrium was attained. The percentage removal of phosphorus exceeded $97 \%$ at $0.5 \mathrm{~h}$ of contact time as to modified clinoptilolite. Whereas, the percentage removal of phosphorus increases rapidly within 2.0 $\mathrm{h}$ and almost remains constant after $6.0 \mathrm{~h}$ of contact time on natural clinoptilolite. It was probably that the observed adsorption was only physical adsorption. ${ }^{[24]}$ The phenomenon indicated that the adsorption capacity of modified clinoptilolite was significantly improved comparing to natural clinoptilolite. Therefore, from the perspective of saving time, $2.0 \mathrm{~h}$ was considered as proper contact time. As the experiment went on, mass transfer rates in inner porous generally slowed down and adsorption capacity increased with time, until to reach dynamic equilibrium. When time was $2.0 \mathrm{~h}$, the reaction was nearly close to equilibrium, there was no need to continue. Assuming the adsorption process was given priority to surface adsorption. After adsorption reached saturation at the surface of adsorbent, phosphorus went inside and bound on the adsorbent sites in clinoptilolite.

According to the above described results of preliminary experiments, it was tempting to conclude that the removal ratio of total phosphorus can reach above $99.45 \%$ at optimal experimental conditions. For the phosphorus adsorption from $50 \mathrm{~mL}$ stimulated wastewater, the superior operational factors were as follows: $\mathrm{pH}$ value was 8.0, adsorbent dosage was 5 $\mathrm{g}$, system temperature was $303 \mathrm{~K}$ and contact time was $2.0 \mathrm{~h}$. 

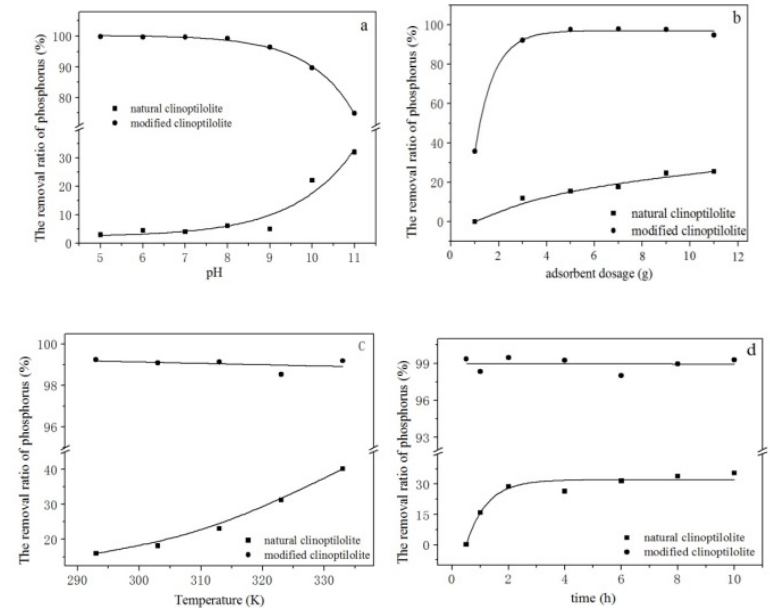

Figure.2 The effects of operational factors on phosphorus removal ratio. (a) $\mathrm{pH}$; (b) adsorbent dosage; (c) temperature; (d) time.

\subsection{XRD And FT-IR Studies}

The X-ray diffraction (XRD) patterns of the clinoptilolite, modified clinoptilolite as well as modified clinoptilolite after adsorption phosphate were illustrated in Figure.3. Comparing Figure.3 (b) with 3 (a), there are no new peaks appeared. This suggests that lanthanum hydroxide appeared as an amorphous phase. ${ }^{[25]}$ And the peaks intensity was decreased that may due to the formation of lanthanum hydroxide. The results of EDS in Table 1 also indicated that lanthanum appeared on the surface of the clinoptilolite. Comparing Figure.3 (c) with 3 (b), the newly-emerged peaks indicated that this can be indexed as a monoclinic $\mathrm{LaPO}_{4}$ phase. The covering of the newly-formed $\mathrm{LaPO}_{4}$ phase further weakened the original crystalline peaks. Recent studies on sorption of phosphate by La loaded mesoporous silica SBA-15 ${ }^{[26]}$ also confirmed the formation of $\mathrm{LaPO}_{4}$ phase.

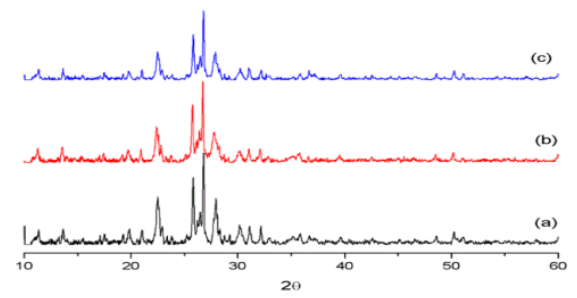

Figure.3 XRD patterns of (a) natural clinoptilolite, (b) modified clinoptilolite, and (c) modified clinoptilolite after

$$
\text { adsorption phosphate }
$$

FT-IR spectra of natural clinoptilolite, modified clinoptilolite and modified clinoptilolite after adsorption phosphate were presented in Figure.4. Comparing Figure.4 (b) with 4 (a), new peaks at $\sim 688 \mathrm{~cm}^{-1}$ and $\sim 543 \mathrm{~cm}^{-1}$ were found to be the characteristic frequency of $\mathrm{La}-\mathrm{OH}$ bond vibration in $\mathrm{La}(\mathrm{OH})_{3} .{ }^{[27-28]}$ This indicated that $\mathrm{La}(\mathrm{OH})_{3}$ was loaded onto the surface of modified clinoptilolite, which was also manifested with the presence of the 
lanthanum hydroxide particles from the XRD pattern of modified clinoptilolite. By comparing the FT-IR spectra of Figure. 4 (c) with 4 (b), the strong absorption peak at about $1,050 \mathrm{~cm}^{-1}$ was attributed to the typical characteristic of the asymmetric stretch vibration of $\mathrm{P}-\mathrm{O}$ of $\mathrm{PO}_{4}{ }^{3-}$ group on modified clinoptilolite after adsorption phosphate, ${ }^{[29-30]}$ so direct evidence of $\mathrm{PO}_{4}{ }^{3-}$ in modified clinoptilolite after adsorption phosphate was obtained. It can be also observed the bands at $\sim 613 \mathrm{~cm}^{-1}$ and $\sim 538 \mathrm{~cm}^{-1}$ were attributed to the bend vibration of $\mathrm{O}-\mathrm{P}-\mathrm{O},{ }^{[31]}$ indicating that the active $\mathrm{La}$ sites had reacted with phosphate.

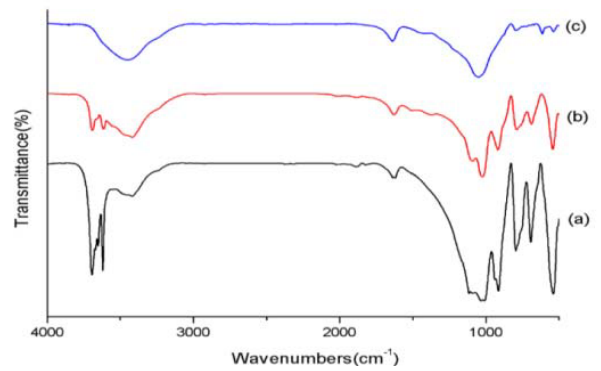

Figure.4 FT-IR patterns of (a) natural clinoptilolite, (b) modified clinoptilolite, and (c) modified clinoptilolite after adsorption phosphate

In general consideration, phosphorus adsorption mechanism of metal (hydr)oxides might account for Lewis acid-base interactions, electrostatic and ion exchange. ${ }^{[32]}$ The La-modified clinoptilolite shows great affinity toward phosphate probably due to the existence of the above-mentioned three interactions.

\subsection{Adsorption Isotherm}

The initial and equilibrium concentration of the adsorbed species are important parameters to measure the performance of the adsorbent. From the experimental results, it can be found that when increasing concentrations of phosphorus can increase in its uptake.

In order to understand the phosphorus adsorption mechanism of natural and modified clinoptilolite, the experimental data obtained for phosphorus adsorption at $303 \mathrm{~K}$ were fitted to Langmuir and Freundlich adsorption model. The values of Langmuir constant $\mathrm{K}_{\mathrm{L}}$, monolayer capacity of adsorbent $\left(\mathrm{q}_{\mathrm{m}}\right)$ and $\mathrm{R}^{2}$ were listed in Table 2 . High $\mathrm{K}_{\mathrm{L}}$ value showed the high affinity of adsorbents for phosphorous adsorption. The obtained $\mathrm{R}^{2}$ values confirmed that the adsorption equilibrium data fitted well to the Langmuir model. Based on the Langmuir adsorption model, the predicted maximum monolayer phosphorous adsorption capacity of natural and modified clinoptilolite at $303 \mathrm{~K}$ was found to be 0.6508 $\mathrm{mg} \cdot \mathrm{g}^{-1}$ and $1.4941 \mathrm{mg} \cdot \mathrm{g}^{-1}$ respectively. The adsorption capacity was much higher than the data reported by Selma C. Ayaz et al. ${ }^{[33]}$ The $\mathrm{R}_{\mathrm{L}}$ parameter was considered as a more reliable indicator for adsorption. $\mathrm{R}_{\mathrm{L}}$ values tabulated in Table 2 for phosphorus adsorption on natural and modified clinoptilolite were found to be positive and the results less than unity indicating the adsorption effect is remarkable. ${ }^{[34]}$ 
Table 2 Constants Of Isotherms For Phosphorus Adsorption On Natural And Modified Clinoptilolite

\begin{tabular}{|c|c|c|c|c|c|}
\hline \multirow{2}{*}{ Isotherm } & & \multicolumn{4}{|c|}{ parameter } \\
\hline \multirow{2}{*}{ Langmuir } & Adsorbent & $\mathrm{q}_{\mathrm{m}}$ & $\mathrm{K}_{\mathrm{L}}$ & $\mathrm{R}^{2}$ & $\mathrm{R}_{\mathrm{L}}$ \\
\hline & Natural clinoptilolite & 0.6508 & 0.1579 & 0.9958 & 0.0257 \\
\hline & Modified clinoptilolite & 1.4941 & 0.0958 & 0.9080 & 0.0417 \\
\hline Freundlich & Adsorbent & $\mathrm{K}_{\mathrm{F}}$ & $1 / \mathrm{n}$ & $\mathrm{R}^{2}$ & \\
\hline & Natural clinoptilolite & 0.1105 & 0.4101 & 0.7793 & \\
\hline & Modified clinoptilolite & 0.1417 & 0.6454 & 0.9884 & \\
\hline
\end{tabular}

The Freundlich adsorption isotherm is a particular instance for complex surface energy. In that case, the energy varies as a function of surface coverage strictly as the change of adsorption in the Langmuir equation. The adsorption process's favorable condition is $0.1<$ $1 / \mathrm{n}<1 .{ }^{[34]}$ The values of $\mathrm{K}_{\mathrm{F}}, 1 / \mathrm{n}$ and $\mathrm{R}^{2}$ were listed in Table 2 . The high correlation coefficients $\left(\mathrm{R}^{2}=0.9884\right)$ reflected that the experimental data of modified clinoptilolite agreed well with the Freundlich adsorption model. And the condition mentioned above was followed by $1 / \mathrm{n}$ values, which indicated that the phosphorus adsorption of natural and modified clinoptilolite was a beneficial process. On the basis of the statistical theory of adsorption, $1 / \mathrm{n}<1$ indicates that between the adsorbed molecules or ions the surface of the synthetic material with minimal interactions. From the results, the adsorption process was favorable under studied conditions, and the clinoptilolite had good adsorption capacity for phosphorus removal from aqueous system.

In view of natural clinoptilolite, the experimental results showed that the correlation coefficients $\left(\mathrm{R}^{2}\right)$ of Langmuir adsorption was higher than that of Freundlich adsorption, which meant that the phosphorus adsorption type of natural clinoptilolite was a monolayer adsorption reaction. Adsorption process of modified clinoptilolite, by contrast, was in better accordance with the Freundlich equation than the Langmuir equation indicating that the adsorption type involved multi molecular layers with a non-uniform distribution.

\subsection{Adsorption Kinetics Model}

Appling the optimum experimental conditions to evaluate the effectiveness of modified clinoptilolite in reducing phosphorus concentration from bovine urine wastewater. The results demonstrated that the removal ratio of phosphorus could be reached as high as $98.38 \%$, which was significantly higher than that of natural one (nearly close to $40 \%$ ). It also indicated that modified clinoptilolite could be efficiently used in controlling phosphorus level from bovine urine wastewater. In addition, it was astonished to find out that the removal efficiency was elevated when natural clinoptilolite applied to real wastewater. Guessing the possible reason was as follows: total phosphorus in wastewater can be separated into inorganic and organic phosphorus. Bovine urine as organic animal digestion contains a considerable amount of organic phosphorus. While stimulated wastewater was just consisted of inorganic phosphorus. As above discussed, it may be concluded that the adsorption efficiency of La-modified clinoptilolite on organic phosphorus was much better than that on inorganic phosphorus. However, when it came to modified clinoptilolite, the difference was too minor to be concerned. After that, in order to further investigate the variation pattern of modified clinoptilolite in adsorbing phosphorus from real wastewater, the dynamic experiments were conducted. The experimental data was fitted to pseudo-first-order and pseudo-second-order kinetic equations. The results were shown in Figure.5. 

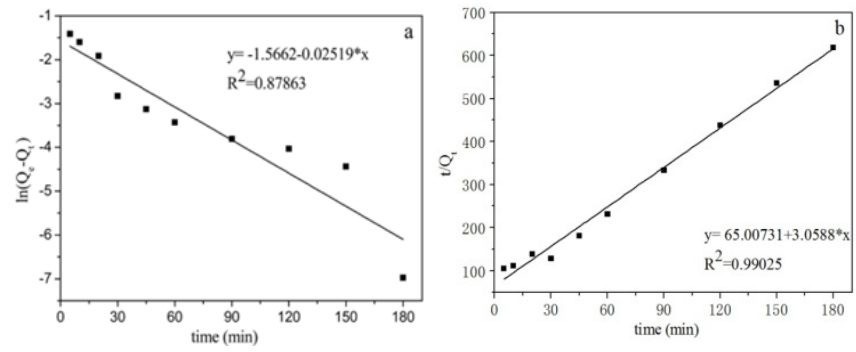

Figure.5 The pseudo-first-order (a) and pseudo-second-order (b) kinetics curve of modified clinoptilolite on

phosphorus adsorption.

As could be seen from adsorption kinetics curve (data not shown) that the characteristics of modified clinoptilolite adsorption phosphorus is a process by fast adsorption and slow balance, with the passage of time. When the adsorption reaction for 45 min, a rapid increase in the rate of adsorption of phosphorus and a high amount of phosphorus adsorption. When the reaction for $60 \mathrm{~min}$, the adsorption rate slows, but it does not reach the adsorption equilibrium and the content of the adsorption phosphorus still increases. It was revealed by Cheng Jiang et al that due to the continuous decrease in the driving force $\left(\mathrm{Q}_{\mathrm{e}}-\mathrm{Q}_{\mathrm{t}}\right)$, the adsorption rate decreased with time until it gradually reached to the equilibrium. ${ }^{[35]}$ After adsorption for $180 \mathrm{~min}$, phosphorus adsorption almost equilibrium and dynamic adsorption equilibrium process began.

Based on the correlation coefficient $\left(\mathrm{R}^{2}\right)$ of the pseudo-first-order and pseudo-second-order kinetics, the pseudo-second-order kinetics equation was better in describing the adsorption kinetics of phosphorus by modified clinoptilolite. According to pseudo-second-order kinetic model, the phosphorus removal process in wastewater was dominated by chemical adsorption. The results were in consistence with former assumption.

\section{Conclusions}

The modified clinoptilolite obtained by lanthanum chloride modification had efficient adsorption for phosphorus removal. The synthetic method of adsorbent is a convenient, low cost and green chemical pathway, which is available for industrial application. Experimental results showed that the adsorption of phosphorus onto modified clinoptilolite was more inclined to chemical combination, resulting in the rapid adsorption rate. The adsorption capacity of clinoptilolite was improved significantly after modification, which was more than triple than that of natural one. The removal efficiency strongly depended on $\mathrm{pH}$. The removal ratio of phosphorus from real wastewater could be reach as high as $98.38 \%$, while the concentration of phosphorus in the external solution was below 0.81 $\mathrm{mg} \cdot \mathrm{L}^{-1}$. The Freundlich isotherm model was better than Langmuir in describing the adsorption process. Also the adsorption process was well fitted to pseudo-second-order kinetic model. In addition, La-modified clinoptilolite could be applied to separate different forms of phosphorus from wastewater. Further practical application should be enhanced for future sustainability in industrial wastewater treatment due to its high efficiency, low coat and good regeneration. 


\section{Acknowledgement}

The authors acknowledge the research grant provided by the national science and technology major project for water pollution control and management (Project No. 2014ZX07105-001).

\section{References}

1. $\quad$ K. Sethi and V. K. Dwivedi, Desalin. Water Treat., 51, 7394(2013).

2. V. H. Smith and D. W. Schindler, Trends Ecol. Evol., 24, 201(2009).

3. T. C. Daniel, A. N. Sharpley, J. L. Lemunyon and J. Environ. Qual., 27, 251(1998).

4. D. W. Schindler, Proc. R. Soc. B., 279, 4322(2012).

5. H. X. Huo, H. Lin, Y. B. Dong, H. Cheng, H. Wang and L. X. Cao, J. Hazard. Mater., 229, 292(2012).

6. $\quad$ K.Y. Foo and B.H. Hameed, J. Hazard. Mater., 171, 54(2009).

7. F. Haghseresht, S. B. Wang and D. D. Do, Appl. Clay Sci., 46, 369(2009).

8. Y. Zhan, J. Lin and Z. Zhu, J. Hazard. Mater., 186, 1972(2011).

9. S. Tokunaga, S. A. Wasay and S. W. Park, Water Sci. Technol., 35, 71(1997).

10. H. Lin, L. Y. Jiang, Z. Y. Zhao and Y. F. Chen, J. Univ. Sci. Technol. Beijing, 31, 551(2009).

11. P. Sharma and W.J. Chung, Desalination, 275, 172(2001).

12. Langmuir, J. Am. Chem. Soc., 40, 1361(1918).

13. T. W. Weber and R. K. Chakraborti, Am. Inst. Chem. Eng., 20, 228(1974).

14. H. M. F. Freundlich, J. Phys. Chem., 57, 385(1906).

15. E. D. Nicola, S. M. Merie, M. Gallo, M. Iaccarino, C. D. Rocca, G. Lofrano, T. Russo and G. Pagano, Environ. Pollut. , 146, 46(2007).

16. J. N. Wang, A. M. Li, L. Xu and Y. Zhou, J. Hazard. Mater., 169, 794(2009).

17. Schroeder, Soils-facts and concepts, Potash Institute, Bern (1984).

18. S. L. Tisdale, W. L. Nelson and J. D. Beaton, Soil fertility and fertilizers, Macmillan Publishing Company, New York (1985).

19. N. M. Dibtseva and K. I. Kienskaya, Colloid J., 63, 150(2001).

20. J. Xie, Z. Wang, S. Y. Lu, D. Y. Wu, Z. J. Zhang and H. N. Kong, Chem. Eng. J., 254, 163(2014).

21. Z. H. Li and R. Bowman, Environ. Sci. Technol., 31, 2407(1997).

22. J. A. Dean, Lange's handbook of chemistry, McGraw-Hill, New York (1985).

23. N.J. Barrow, J. Soil Sci., 37, 277(1986).

24. D. Bhardwaj, M. Sharma, P. Sharma and R. Tomar, J. Hazard. Mater, 227, 292(2012).

25. J. Xie, Z. Wang, D. Fang, C. J. Li and D. Y. Wu, Journal of Colloid Science, 423, 13(2014).

26. E. W. Shin, K. G. Karthikeyan and A. Mandla, Environ. Sci. Technol., 39, 6273(2005).

27. M. Aghazadeh, A. N. Golikand, M. Ghaemi and T. Yousefi, Mater. Lett., 65, 1466(2011).

28. L. Zhang, L. Wan, N. Chang, J. Liu, C. Duan, Q. Zhou, X. Li and X. Wang, J. Hazard. Mater., 190, 848(2011).

29. H. Li, J. Ru, W. Yin, X. Liu, J. Wang and W. Zhang, J. Hazard. Mater., 168, 326(2009).

30. D. Soejoko and M. Tjia, J. Mater. Sci., 38, 2087(2003).

31. L. Li, W. Jiang, H. Pan, X. Xu, Y. Tang, J. Ming, Z. Xu and R. Tang, The Journal of Physical Chemistry C, 111, 4111(2007).

32. Z. G. Ling, H. Li, N. Wa, C. Ning, J. Y. Liu, D. Chao, Q. Zhou and X. L. Li, J. Hazard. Mater., 190, 848(2011). 
33. S. C. Ayaz, O. Aktas, N. Findik and L. Akca, Desalin. Water Treat., 37, 152(2012).

34. H. B. Senturk, D. Ozdes, A. Gundogdu, C. Duran and M. Soylak, J. Hazard. Mater, 172, 353(2009).

35. Jiang, L. Y. Jia, Y. L. He, B. Zhang, G. Kirumba and J. Xie, J. Colloid Interface Sci., 402, 246(2013). 